\title{
The Relationship Between Type 2 Diabetes Mellitus and Osteoporosis in Elderly Patients: A Retrospective Study
}

\author{
Soha Abd El Aziz Abd El Aal, Anood Jamal Alshaali*, Mohammed Hammam
} Fawzy, Mona Sobhy Elsherbiny and Amal Mohamad AlJaziri

Geriatric medicine section, Primary Health Care Sector, Dubai Health Authority, Dubai, United Arab Emirates

ISSN: 2639-0531

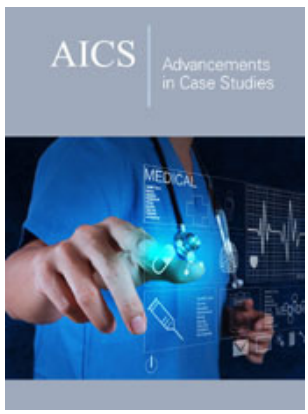

*Corresponding author: Anood Jamal Alshaali, Geriatric medicine section, Primary Health Care Services Sector, Dubai Health Authority, Dubai, United Arab Emirates

Submission: 梅 November 16, 2020

Published: 眥 December 03, 2020

Volume 2 - Issue 5

How to cite this article: Soha Abd El Aziz Abd El Aal, Anood Jamal Alshaali*, Mohammed Hammam Fawzy, Mona Sobhy Elsherbiny, Amal Mohamad AlJaziri. The Relationship Between Type 2 Diabetes Mellitus and Osteoporosis in Elderly Patients: A Retrospective Study. Adv Case Stud. 2(5). AICS.000549. 2020 DOI: 10.31031/AICS.2020.02.000549

Copyright@ Anood Jamal Alshaali, This article is distributed under the terms of the Creative Commons Attribution 4.0 International License, which permits unrestricted use and redistribution provided that the original author and source are credited.

\section{Abstract}

Type 2 diabetes mellitus (T2DM) effect bone metabolism, but the relationship of T2DM with bone mineral density remains inconsistent across studies. The objective of this study was to determine the relationship between osteoporosis and T2DM in elderly patients.A total of 313 elderly was included in the study with a mean age of $68.20 \pm 7.07$ years. The prevalence of osteoporosis in this study was $39.5 \%$. The results showed that, non- diabetic elderly had higher prevalence of osteoporosis in comparison to diabetic elderly $(44.0 \%$ and $33.1 \%$, respectively). This difference was statistically significant $(\mathrm{P}=0.007)$. It was observed that males had higher femur and lumbar spine BMD in comparison with females. The present study gave better understanding of the effect of diabetes mellitus on bone architecture will help to improve the quality of provided health services at the primary health care level hence, improving the outcomes.

Keywords: Osteoporosis; Type 2 diabetes mellitus;Bone mineral density; Primary health care (PHC), Dubai health authority (DHA)

\section{Introduction}

Osteoporosis is defined as a metabolic skeletal disorder characterized by compromised bone strength and altered bone quality along with micro-architectural abnormalities predisposing a person to an increased risk of fracture, hence leading to a significant morbidity and mortality [1,2]. The risk of osteoporosis increases with advanced age and is higher in women than in men. The lifetime risk of developing osteoporosis and osteoporotic fracture is estimated to be $30-50 \%$ in women and $15-30 \%$ in men [3]. The United Nation described population aging as a key demographic feature of the 20th century and stated that it will remain an important population issue throughout the 21st century. Elderly population forms a significant proportion of the world total population. In $2015,12 \%$ of the 7.3 billions living individuals were aged 60 years and above. This is expected to increase to $21.6 \%$ by 2050 [4].

The proportion of elderly in the United Arab Emirates population is increasing constantly. The UAE population above 60 years of age was $5.1 \%$ in $2000 \%$ and expected to reach $23.6 \%$ in 2025 [5]. A study conducted in the primary health care facilities in Dubai reported that the prevalence of osteoporosis in elderly was $8.3 \%$. A higher prevalence was noted among female compared to male (12.9\% and $2.4 \%$ respectively) [6]. Like osteoporosis, type 2 diabetes mellitus (T2DM) is also highly prevalent in aging populations, putting this group at higher risk of bone fracture. Demographic trends with longer life expectancy and a lifestyle characterized by low physical activity and high-energy food intake contribute to the increasing incidence of type 2 diabetes mellitus and osteoporosis [7].

Despite the presence of different reports describing skeletal disorders among patients with type 2 diabetes mellitus, controversy remains concerning the risk of osteoporosis and its clinical importance among these patients [8]. Studies on the association between bone 
mineral density (BMD) and type 2 diabetes mellitus revealed conflicting results with variations towards higher [9-11] normal $[12,13]$ and lower values [14-17] of BMD in patient with T2DM. A study conducted among diabetic females in the UAE reported that the BMD were similar in diabetic and control groups [12]. A second study was conducted in UAE reported that osteoporosis was significantly higher in diabetic group [14].

A better understanding of the effect of diabetes mellitus on bone architecture will help to improve the quality of provided health services at the primary health care level hence, improving the outcomes. This study is conducted to determine the relationship between osteoporosis and type 2 diabetes mellitus in elderly patients and type 2 diabetes mellitus in elderly patients.

\section{Methodology}

Study design and setting: Retrospective study was conducted in osteoporosis clinic in the primary health care center in Dubai health authority.

Target population: Elderly aged 60 years and above attended the osteoporosis clinic for screening in the primary health care centre in Dubai health authority in 2018.

\section{Exclusion criteria:}

A. patients with malignancy

B. patients with untreated hyperthyroidism and hyperparathyroidism

C. patients with diagnosed diffuse connective tissue disease (Rheumatoid arthritis, poliomyelitis, and dermatomyositis)

D. patients with liver and / or renal faliure

E. patients diagnosed previously as osteoporotic patients and receiving treatment (antiresorptive, bone forming, HRT, and SERM)

F. patients with solid organ or bone marrow transplant

G. immobilized patients for more than one year

H. patients on the following medications

a. anticoagulants

b. antiepileptic(phenobarbital, phenytoin, carbamazepine)

c. hormonal replacement therapy

d. chemotherapeutic drugs

e. glucocorticoids more than $5 \mathrm{mg}$ for $\geq 3$ months

\section{Data collection}

The Dubai Health Authority has an electronic medical system and the patient electronic medical record was used as a source for data collection. The data collected aimed at eliciting the following information
A. Demographic data including age, sex, nationality and Body mass index (BMI).

B. Diabetes history and if yes then the duration of the disease was recorded.

C. Lab investigations results including HBA1C, creatinine, Vitamin D and calcium.

D. Bone Mineral Density Measurement results

\section{Definitions of the study variables}

Body Mass Index (BMI) was categorized by WHO as follows: elderly with BMI $<18.5 \mathrm{~kg} / \mathrm{m}^{2}, 18.5-24.9 \mathrm{~kg} / \mathrm{m}^{2}, 25.0-29.9 \mathrm{~kg} / \mathrm{m}^{2}$ or $\geq 30.0 \mathrm{~kg} / \mathrm{m}^{2}$ are defined as underweight, normal, overweight or obese respectively [18]. Bone Mineral Density (BMD) Measurement. The BMD of the hip and the lumbar spine was measured using dual energy X-ray absorptiometry (DEXA) (Lunar, GE Health Care) and the result was expressed as BMD, T-score and Z score. The reference standard of a T-score is the peak bone density, as reached in men or women between 20-30 years of age. The T-score is then defined as the number of standard deviations from this score. According to the WHO definition, "osteoporosis" is defined as a T-score equal to or lower than -2.5,"osteopenia" is defined as a T-score between -2.5 and -1.0 ,and when the T-score is equal to greater than -1.0 BMD is "normal" [19].

\section{Ethical consideration}

The procedures used were approved by the Research Ethics Committee (Medical Research Section, Dubai Health Authority, Dubai, UAE).

\section{Data analysis}

Statistical Package for social science (SPSS) program version 20 was used for analysis of data as follows:

(i) Descriptive statistics were carried out in the form of mean, standard deviation, and range for quantitative values.

(ii) Frequency and percentage were done for qualitative variables

(iii)Mean and SD were calculated for different continuous variables, and student's t test was used to compare mean values to test the significance level.

(iv) Categorical variables are expressed as percentage, and chisquare test was used to assess the statistical significance level. $P$ value $<0.05$ was considered statistically significant with $95 \%$ confidence interval.

\section{Results}

The present study comprised 313 elderly, most of whom were in the age range 60years to $<70$ years $(64.4 \%)$ with a mean age of $68.20 \pm 7.07$ years. More than $70 \%$ of elderly were female and the majority were local to the UAE (89.1\%). It was found that $51.1 \%$ of elderly were obese and $31.5 \%$ were overweight. (Table 1). As 
shown in Table 2, 39.5\% of the elderly who were newly referred to the osteoporosis clinic were osteoporotic and $40.8 \%$ of the elderly were diabetic. The mean duration for diabetic elderly was 13.34 \pm 8.77. In Table 3 clinical parameter of elderly with and without diabetes were compared. Vitamin D and HBA1C were significantly higher in diabetic elderly.

Table 1: Distribution of elderly attending the osteoporosis clinic according to personal characteristics.

\begin{tabular}{|c|c|c|}
\hline Personal characteristics & $\mathrm{n}=\mathbf{3 1 3}$ & $\%$ \\
\hline \multicolumn{3}{|c|}{ Age } \\
\hline $60-64$ & 114 & 36.7 \\
\hline $65-69$ & 86 & 27.7 \\
\hline $70-74$ & 54 & 17.4 \\
\hline $75-79$ & 29 & 9.3 \\
\hline $80+$ & 28 & 9.0 \\
\hline mean \pm SD & \multicolumn{2}{|c|}{$68.20 \pm 7.07$} \\
\hline range & \multicolumn{2}{|c|}{$60-99$} \\
\hline \multicolumn{3}{|c|}{ Sex } \\
\hline male & 90 & 28.9 \\
\hline female & 221 & 71.1 \\
\hline \multicolumn{3}{|c|}{ Nationality } \\
\hline UAE national & 277 & 89.1 \\
\hline non-UAE national & 34 & 10.9 \\
\hline \multicolumn{3}{|c|}{ Body mass index (BMI) } \\
\hline underweight $<18.5$ & 9 & 2.9 \\
\hline Normal 18.5-24.99 & 45 & 14.5 \\
\hline Overweight 25-29.99 & 98 & 31.5 \\
\hline Obese $\geq 30$ & 159 & 51.1 \\
\hline mean \pm SD & \multicolumn{2}{|c|}{$30.32 \pm 6.24$} \\
\hline range & \multicolumn{2}{|c|}{$15.15-56.80$} \\
\hline
\end{tabular}

Table 2: Bone Mineral Density (BMD) classification and the prevalence of diabetes mellitus type 2 .

\begin{tabular}{|c|c|c|}
\hline BMD classification & $\mathbf{n = 3 1 3}$ & $\mathbf{\%}$ \\
\hline Normal & 60 & 19.3 \\
\hline Osteopenia & 128 & 41.2 \\
\hline Osteoporosis & 123 & 39.5 \\
\hline Diabetes $\quad 127$ & 40.8 \\
\hline \multicolumn{2}{|c|}{ Diabetic } & 184 \\
\hline non-diabetic & $13.34 \pm 8.77$ \\
\hline $\begin{array}{c}\text { Duration of diabetes for diabetic; } \\
\text { mean } \pm \text { SD (years) }\end{array}$ & \multicolumn{2}{|c|}{} \\
\hline
\end{tabular}

Table 3: Clinical parameter of elderly with and without diabetes (mean $\pm \mathrm{SD}$ ).

\begin{tabular}{|c|c|c|c|}
\hline \multirow{2}{*}{ Clinical parameter } & Diabetes Status & Mean & \multirow{2}{*}{ P- value } \\
\hline \multirow{2}{*}{ HBA1C } & Diabetic & $7.44 \pm 1.42$ & \multirow{2}{*}{0.00} \\
\cline { 2 - 3 } creatinine & Non-diabetic & $5.82 \pm 4.51$ & \\
\cline { 2 - 3 } & Diabetic & $0.75 \pm 0.37$ & \multirow{2}{*}{0.138} \\
\hline \multirow{2}{*}{ calcium } & Non-diabetic & $0.69 \pm 0.24$ & \\
\cline { 2 - 3 } & Diabetic & $9.49 \pm 0.35$ & \multirow{2}{*}{0.350} \\
\hline \multirow{2}{*}{ Vitamin D } & Diabetic & $34.57 \pm 15.08$ & \multirow{2}{*}{0.007} \\
\cline { 2 - 3 } & Non-diabetic & $30.20 \pm 12.99$ & \\
\hline \multirow{2}{*}{ BMI } & Diabetic & $30.98 \pm 6.14$ & \multirow{2}{*}{0.123} \\
\cline { 2 - 3 } & Non-diabetic & $29.87 \pm 6.28$ & \\
\hline
\end{tabular}

It was found that non- diabetic elderly had higher prevalence of osteoporosis in comparison to diabetic elderly $(44.0 \%$ and $33.1 \%$, respectively). This difference was statistically significant $(\mathrm{P}=0.007)$ (Table 4). In Table 5 the mean Femur BMD in nondiabetic was $0.81 \mathrm{~g} / \mathrm{cm}^{2} \pm 0.16$ and in the diabetic was $0.87 \mathrm{~g} / \mathrm{cm}^{2}$ $\pm 1.76(\mathrm{P}=0.004)$. The mean Lumbar spine BMD in non- diabetic $1.00 \mathrm{~g} / \mathrm{cm}^{2} \pm 0.21$ and in the diabetic was $1.04 \mathrm{~g} / \mathrm{cm}^{2} \pm 0.20$, the difference was not statistically significant $(\mathrm{P}=0.071)$. As shown in Table 6, the mean Femur BMD in non- diabetic male was lower in comparison to diabetic male $\left(0.90 \mathrm{~g} / \mathrm{cm}^{2} \pm 0.17\right.$ and $0.94 \mathrm{~g} / \mathrm{cm}^{2} \pm$ 0.14 respectively). The difference was statistically not significant $(\mathrm{P}=0.218)$. In Table 7 the mean Femur BMD in non-diabetic male was lower in comparison to diabetic female $\left(0.77 \mathrm{~g} / \mathrm{cm}^{2} \pm 0.15\right.$ and $0.84 \mathrm{~g} / \mathrm{cm}^{2} \pm 0.18$ respectively). The difference was statistically significant $(\mathrm{P}=0.003)$.

Table 4: Distribution and the percentage of Bone Mineral Density (BMD) in diabetics and non-diabetics elderly.

\begin{tabular}{|c|c|c|c|c|}
\hline \multirow{2}{*}{} & \multicolumn{3}{|c|}{ BMD classification } & \multirow{2}{*}{ P- value } \\
\cline { 2 - 4 } & Normal & Osteopenia & Osteoporosis & \\
& $\mathrm{N}(\%)$ & $\mathrm{N}(\%)$ & $\mathrm{N}(\%)$ & \\
\hline \multirow{2}{*}{ Diabetics } & $35(27.6 \%)$ & $50(39.4 \%)$ & $42(33.10 \%)$ & \multirow{2}{*}{0.007} \\
\hline \multirow{2}{*}{ Non- diabetics } & $25(13.6 \%)$ & $(42.40 \%)$ & $81(44.00 \%)$ & \\
\hline
\end{tabular}


Table 5: Distribution of Bone Mineral Density (BMD) T score and $Z$ score in diabetics and non-diabetics elderly.

\begin{tabular}{|c|c|c|c|}
\hline Variable & $\begin{array}{l}\text { Diabetes } \\
\text { Status }\end{array}$ & Mean & P-value \\
\hline \multirow[t]{2}{*}{ Femur BMD $\left(\mathrm{g} / \mathrm{cm}^{2}\right)$} & Diabetic & $0.87 \pm 1.76$ & \multirow[t]{2}{*}{0.004} \\
\hline & Non- diabetic & $0.81 \pm 0.16$ & \\
\hline \multirow{2}{*}{ Femur T score } & Diabetic & $-1.25 \pm 1.15$ & \multirow[t]{2}{*}{0.001} \\
\hline & Non- diabetic & $-1.67 \pm 1.12$ & \\
\hline \multirow{2}{*}{ Femur Z score } & Diabetic & $0.124 \pm 1.11$ & \multirow[t]{2}{*}{0.00} \\
\hline & Non- diabetic & $-0.29 \pm 0.95$ & \\
\hline \multirow[t]{2}{*}{ Lumbar spine BMD $\left(\mathrm{g} / \mathrm{cm}^{2}\right)$} & Diabetic & $1.04 \pm 0.20$ & \multirow[t]{2}{*}{0.071} \\
\hline & Non- diabetic & $1.00 \pm 0.21$ & \\
\hline \multirow[t]{2}{*}{ Lumbar spine $\mathrm{T}$ score } & Diabetic & $-1.24 \pm 1.60$ & \multirow[t]{2}{*}{0.062} \\
\hline & Non- diabetic & $-1.59 \pm 1.67$ & \\
\hline \multirow[t]{2}{*}{ Lumbar spine Z score } & Diabetic & $-0.28 \pm 1.39$ & \multirow[t]{2}{*}{0.071} \\
\hline & Non- diabetic & $-0.57 \pm 1.42$ & \\
\hline
\end{tabular}

Table 6: Distribution of Bone Mineral Density (BMD) $T$ score and $Z$ score in diabetics and non-diabetics elderly male.

\begin{tabular}{|c|c|c|c|}
\hline Variable & Diabetes Status & Mean & P-value \\
\hline \multirow[t]{2}{*}{ Femur BMD $\left(\mathrm{g} / \mathrm{cm}^{2}\right)$} & Diabetic & $0.94 \pm 0.14$ & \multirow{2}{*}{0.218} \\
\hline & Non- diabetic & $0.90 \pm 0.17$ & \\
\hline \multirow{2}{*}{ Femur T score } & Diabetic & $-0.83 \pm 1.10$ & \multirow{2}{*}{0.250} \\
\hline & Non- diabetic & $-1.13 \pm 1.25$ & \\
\hline \multirow{2}{*}{ Femur Z score } & Diabetic & $0.20 \pm 1.11$ & \multirow{2}{*}{0.332} \\
\hline & Non- diabetic & $-0.03 \pm 1.10$ & \\
\hline \multirow{2}{*}{$\begin{array}{l}\text { Lumbar spine BMD (g/ } \\
\left.\qquad \mathrm{cm}^{2}\right)\end{array}$} & Diabetic & $1.17 \pm 0.24$ & \multirow{2}{*}{0.258} \\
\hline & Non- diabetic & $1.12 \pm 0.20$ & \\
\hline \multirow[t]{2}{*}{ Lumbar spine T score } & Diabetic & $-0.33 \pm 1.95$ & \multirow{2}{*}{0.304} \\
\hline & Non- diabetic & $-0.73 \pm 1.64$ & \\
\hline \multirow[t]{2}{*}{ Lumbar spine Z score } & Diabetic & $-0.03 \pm 1.85$ & \multirow{2}{*}{0.419} \\
\hline & Non- diabetic & $-0.31 \pm 1.46$ & \\
\hline
\end{tabular}

Table 7: Distribution of Bone Mineral Density (BMD) $\mathrm{T}$ score and $Z$ score in diabetics and non-diabetics elderly female.

\begin{tabular}{|c|c|c|c|}
\hline Variable & Diabetes Status & Mean & P-value \\
\hline \multirow{2}{*}{$\begin{array}{c}\text { Femur BMD }(\mathrm{g} / \\
\left.\mathrm{cm}^{2}\right)\end{array}$} & Diabetic & $0.84 \pm 0.18$ & \multirow{2}{*}{0.003} \\
\hline & Non-diabetic & $0.77 \pm 0.15$ & \\
\hline \multirow{2}{*}{ Femur T score } & Diabetic & $-1.14 \pm 1.13$ & \multirow{2}{*}{0.001} \\
\hline & Non-diabetic & $-1.90 \pm 0.98$ & \\
\hline \multirow{2}{*}{ Femur Z score } & Diabetic & $0.09 \pm 1.11$ & \multirow{2}{*}{0.000} \\
\hline & Non-diabetic & $-0.40 \pm 0.86$ & \\
\hline \multirow{2}{*}{$\begin{array}{l}\text { Lumbar spine } \\
\text { BMD }\left(\mathrm{g} / \mathrm{cm}^{2}\right)\end{array}$} & Diabetic & $1.00 \pm 0.16$ & \multirow{2}{*}{0.073} \\
\hline & Non- diabetic & $0.95 \pm 0.19$ & \\
\hline \multirow{2}{*}{$\begin{array}{l}\text { Lumbar spine } \mathrm{T} \\
\text { score }\end{array}$} & Diabetic & $-1.58 \pm 1.30$ & \multirow[b]{2}{*}{0.056} \\
\hline & Non-diabetic & $-1.96 \pm 1.55$ & \\
\hline \multirow{2}{*}{$\begin{array}{l}\text { Lumbar spine } \mathrm{Z} \\
\text { score }\end{array}$} & Diabetic & $-0.38 \pm 1.17$ & \multirow{2}{*}{0.083} \\
\hline & Non-diabetic & $-0.69 \pm 1.39$ & \\
\hline
\end{tabular}

\section{Discussion}

In 313 elderly evaluated in our study, the prevalence of osteoporosis in this study was 39.5\%, higher than a study conducted by Al Yousef et al. [6] who reported that prevalence of osteoporosis was $8.3 \%$ among elderly attending the primary health care facilities in Dubai. This could be explained by the patient in this study at high risk of osteoporosis as they referred after being screened by family physician for osteoporosis. Patients identified as having high risk were referred to osteoporosis clinic for DEXA and further assessment.

The investigations of the clinical relevance of osteoporosis in type 2 diabetes mellitus, appear conflicting, and to date, no clear findings have been reached due to the inconsistent findings among researchers [20]. Our data showed that nondiabetics were at a higher risk of developing osteoporosis than T2DM elderly. This finding is consistent with previous studies in Kuwait [9], Jordan [10] and Iran [11] which showed that T2DM is a promoter for bone health. Furthermore, studies have reported that Magnesium deficiency is linked to osteoporosis, insulin resistance and Alzheimer's disease. This could explain that magnesium deficiency in nondiabetics increased the risk for osteoporosis compared to diabetic who consume appropriate magnesium through diet to prevent insulin resistance and therefore prevent osteoporosis [2124].

In contrast, several studies done in UAE [14], Saudi [25] and china [17] showed that T2DM patients were at higher risk for 
osteoporosis. This persistent controversy is probably largely related to the complex pathophysiology of type 2 diabetes and the vast differences in study designs, selection of patients, different diseases stages and BMD measurement technology. It was generally assumed that osteoporosis is less common in men than women. The difference in men and women may be caused by the fact that overall men have a greater BMD at all sites and loose bone at a lower rate than women do [26]. This is in agreement with our study, which reported higher femur and lumbar spine BMD in males in comparison with females.

BMD is used as an indicator for assessing susceptibility to osteoporosis [19]. BMD was analyzed at two sites-femur and lumbar spine using DEXA. BMD was lower in femur indicating higher prevalence of osteoporosis at hip than at lumbar spine.

This observed prevalence of osteoporosis at hip is similar to the finding from Leidig-Bruckner et al. [27] in patients with T2DM who reported the greater prevalence of osteoporosis at hip than at spine. This finding needs further exploration to determine the factors that could contribute to differential rate of bone loss from two sites. The present study revealed that vitamin D was higher in diabetic elderly compared to non- diabetic. This finding in congruent with chen et al. [17] which reported that elderly diabetic men had a higher vitamin D in comparison to non-diabetic. This could be due to the regular comprehensive care provided to the diabetic patients. Body mass index of the participants in this study ranged from 15.15-6.80. In this study, no significant difference was observed in the BMI of two groups. Similarly, Asokan et al. [15] found no difference in BMI between the diabetic and non-diabetic participants. However these findings were against the observation of Saudi study [25], which showed that low BMI is associated with high risk of osteoporosis.

\section{Conclusion}

The prevalence of osteoporosis in this study was 39.5\%. Our data showed that nondiabetics were at a higher risk of developing osteoporosis than T2DM elderly. BMD in femur was slightly lower than at lumbar spine. The study findings revealed that Vitamin D and HBA1C were significantly higher in diabetic elderly.

\section{References}

1. Klibanski A, Adams-Campbell L, Bassford T (2001) Osteoporosis prevention, diagnosis and therapy. JAMA 285(6): 785-795.

2. Delaney MF, LeBoff MS (2001) Metabolic bone disease. In: Ruddy S, Harris ED, Sledge CD, (Eds.), Kelley's Textbook of Rheumatology. ( $6^{\text {th }}$ edn), WB Saunders Co, Philadelphia, USA 2001:1635-1652.

3. Einhorn T (2014) World congress on osteoporosis, osteoarthritis and musculoskeletal diseases (WCO-IOFESCEO 2014): Meet-the-expert session. Osteoporos Int 25: 151-157.

4. United Nations (2002) World population ageing: 1950-2050. New York: Population division, department of economic and social affairs, United Nations.

5. World Health Organization (2020) A strategy for active, healthy ageing and old age care in the Eastern Mediterranean Region 2006-2015.

6. Yousef NJ, Hussein H, Al Faisal W, Makhlouf MM, Wasfy A (2015) Medical and socio-demographic features of elderly patient population attending primary health care facilities in Dubai, UAE. Advances in Applied Psychology 1(1): 10-14.

7. Saller A, Maggi S, Romanato G, Tonin P, Crepaldi G (2008) Diabetes and osteoporosis. Aging-Clinical and Experimental Research 20(4): 280-289.

8. Jackuliak P, Payer J (2014) Osteoporosis, fractures, and diabetes. Int J Endocrinol 2014: 820615

9. Gupata R, Mohammed AM, Mojiminiyi OA, Alenizi EK, Abdulla NA (2009) Bone mineral density in premenopausal Arab women with type 2 diabetes mellitus. Journal of Clinical Densitometry 12(1): 54-57.

10. Hyassat D, Alyan T, Jaddou H, Ajlouni KM (2017) Prevalence and risk factors of osteoporosis among Jordanian postmenopausal women attending the national center for diabetes, endocrinology and genetics in Jordan. Biores Open Access 6(1): 85-93.

11. Bayani MA, Karkhah A, Hoseini R, Qarouei R, Nourodini HQ, et al. The relationship between type 2 diabetes mellitus and osteoporosis in elderly people: A cross-sectional study. Int Biol Biomed J 2(1) 39-46.

12. Jawhar DS, Hassan NA, Shamssain M (2019) Factors affecting bone mineral density in type 2 diabetic female patients referred to dualenergy x-ray absorptiometry scan (DXA-scan). Orthop Muscular Syst 8(2): 1-8.

13. Anaforoglu I, Nar Demirer A, Bascil Tutuncu N (2009) Prevalence of osteoporosis and factors affecting bone mineral density among postmenopausal Turkish women with type 2 diabetes. J Diabetes Complications 23(1): 12-17.

14. Jawhar DS, Hassan NA, Shamssain M (2020) Dual-energy x-ray absorptiometry scan (DXA) findings in diabetic and non-diabetic female: A retrospective cohort study. Med J Malaysia 75(1): 47-51.

15. Asokan AG, Jaganathan J, Philip R, Soman RR, Sebastian ST, et al. (2017) Evaluation of bone mineral density among type 2 diabetes mellitus patients in South Karnataka. J Nat Sci Biol Med 8(1): 94-98.

16. Thakur AK, Dash S (2018) Estimation of bone mineral density among type 2 diabetes mellitus patients in western Odisha. Int J Res Med Sci 6(2): 459-464.

17. Chen H, Deng L, Li JF (2013) Prevalence of osteoporosis and its associated factors among older men with type 2 diabetes. Int J Endocrinol 2013: 285729.

18. World Health Organization. Global Database on Body Mass Index.

19. WHO scientific group on the assessment of osteoporosis at Primary health Care level.

20. Abdulameer SA, Sahib MN, Sulaiman SA (2018) The prevalence of osteopenia and osteoporosis among Malaysian type 2 diabetic patients using quantitative ultrasound densitometer. Open Rheumatol J 12: 5064.

21. Castiglioni S, Cazzaniga A, Albisetti W, Maier JAM (2013) Magnesium and osteoporosis: Current state of knowledge and future research directions. Nutrients 5(8): 3022-3033.

22. Orchard TS, Larson JC, Alghothani N, Tabaku SB, Cauley JA, et al. (2014) Magnesium intake, bone mineral density, and fractures: results from the women's health initiative observational study. Am J Clin Nutr 99(4): 926933.

23. Martins IJ (2016) Magnesium therapy prevents senescence with the reversal of diabetes and Alzheimer's disease. Health 8(7): 694-710.

24. Paschou SA, Dede AD, Anagnostis PG, Vryonidou A, Morganstein D, et al. (2017) Type 2 diabetes and osteoporosis: A guide to optimal management. J Clin Endocrinol Metab 102(10): 3621-3634.

25. AL-Homood IA, Sheshah I, Mohammed AA, Gasim GI (2017) The Prevalence and risk factors of osteoporosis among a Saudi female diabetic population. Maced J Med Sci 5(2): 177-181. 
26. Lang TF (2011) The bone-muscle relationship in men and women. J Osteoporos. 2011: 702735.
27. Leidig-Bruckner G, Grobholz S, Bruckner T, Scheidt-Nave C, Nawroth P, et al. (2014) Prevalence and determinants of osteoporosis in patients with type 1 and type 2 diabetes mellitus. BMC Endocr Disord 14: 33.

For possible submissions Click below: 